\section{Response to: 'Dual target strategy: a proposal to mitigate the risk of overtreatment and enhance patient satisfaction in rheumatoid arthritis' by Ferreira et al}

I thank Dr Ferreira and colleagues ${ }^{1}$ for their thoughtful response to Overdiagnosis and Overtreatment, ${ }^{2}$ which I entirely agree with and to which I will briefly comment, since their proposal may have important clinical connotations. They argue among others that patient-reported outcomes should better be separated from objective measures for disease activity since the former do not always reflect the inflammatory process itself, a valid argument.

Our classic vision on signs and symptoms in diseases like rheumatoid arthritis (RA) has always been rather unidimensional, with which I mean that we implicitly assign most signs and symptoms reported by patients to the inflammatory (immunological) dysregulations. This has always worked well in clinical trials because patients with high levels of disease activity were strictly selected, and patients with other reasons for (rather vague and sometimes unmeasurable) symptoms not explicitly attributable to the inflammatory process were strictly excluded. Such selected trial patients will improve on average when treated with a drug that suppresses inflammation, even though only part of their symptoms are caused by inflammation. I still think that such phase III trial designs are fit to purpose (drug registration) and will pay off acceptably, but the translation to the clinic is tricky.

Not only do patients in the clinic have lower levels of inflammatory disease activity, they may have many more reasons than only inflammation for reporting excessive pain, fatigue, stiffness, depressed mood, anxiety, fears and so on. In addition, most clinical scenarios are simply incomparable with trial environments. A very common example is the patient who objectively responds well to a bDMARD but is not satisfied because of persistent generalised pain and unbearable fatigue that prevents him from working. As the authors argue, these patients are common in all-day practice, and score 'high' on patient-reported outcomes and disease activity indices. All too often rheumatologists feel pressured to act and change treatment. With multiple biological- and targeted synthetic disease modifying antirheumatic drug (DMARD) treatment options to choose from, it is tempting to start 'cycling with these drugs until you find one that will work well'. This is a modus operandi that I and others carefully endorsed in $2010^{3}$ but that I am more sceptical about now, since it was based on the unidimensional assumption that inflammation causes all symptoms that patients report. Others claim that we should do more and better imaging in those patients to find the 'subclinical inflammation' that must be there so that we subsequently can treat it. ${ }^{4}$

It is easy to see the dangers of such policies (overtreatment) that-I am afraid-are more common than we may think: symptoms that are not the immediate consequence of inflammation will not improve on immunological treatment, but adverse events will still occur, and costs of RA treatment will become unaffordable at a personal and societal level. Needless to say, that strong competitive forces in the marketing departments of pharmaceutical industries will promote rather than hinder cycling with (their) expensive drugs.

The solution that Ferreira et $a l^{1}$ proposeis brilliant in its simplicity: separate objective inflammatory signs and patient-reported impact and use both components in treat to target (T2T) strategies ('dual T2T') to determine if treatment should be changed or intensified. Such a strategy combines our well-developed thoughts about addressing the targets of inflammation, as well as evolving ideas about what adds real value to patients, ideas that give room for multidimensionality as a working model for explaining patient-reported outcomes. I am looking forward to see studies that will provide further ground for this 'paradigm-change'.

\section{Robert B M Landewé 1,2 $^{2}$}

${ }^{1}$ Amsterdam Rheumatology \& Immunology Center, Amsterdam University Medical Centres, Amsterdam, The Netherlands

${ }^{2}$ Rheumatology, Zuyderland Medical Center, Heerlen, The Netherlands

Correspondence to Professor Robert B M Landewé, Amsterdam Rheumatology \& Immunology Center, Amsterdam University Medical Centres, Amsterdam 1105 AZ, The Netherlands; landewe@rlandewe.nl

Handling editor Josef S Smolen

Competing interests None declared.

Patient consent Not required.

Provenance and peer review Commissioned; internally peer reviewed.

(c) Author(s) (or their employer(s)) 2019. No commercial re-use. See rights and permissions. Published by BMJ.

\section{D) Check for updates}

To cite Landewé RBM. Ann Rheum Dis 2019;78:e110.

Received 2 August 2018

Accepted 3 August 2018

Published Online First 20 August 2018

\section{Linked}

- http://dx.doi.org/10.1136/annrheumdis-2018-214199

Ann Rheum Dis 2019;78:e110. doi:10.1136/annrheumdis-2018-214221

\section{REFERENCES}

1 Ferreira RJ, Ndosi M, de Wit M, et al. Dual target strategy: a proposal to mitigate the risk of overtreatment and enhance patient satisfaction in rheumatoid arthritis. Ann Rheum Dis 2018. doi: 10.1136/annrheumdis-2018-214199.

2 Landewé RBM. Overdiagnosis and overtreatment in rheumatology: a little caution is in order. Ann Rheum Dis 2018:annrheumdis-2018-213700 [Epub ahead of print $06 \mathrm{Jul}$ 2018].

3 Ramiro S, Machado P, Singh JA, et al. Applying science in practice: the optimization of biological therapy in rheumatoid arthritis. Arthritis Res Ther 2010:12:220.

4 Gandjbakhch F, Haavardsholm EA, Conaghan PG, et al. Determining a magnetic resonance imaging inflammatory activity acceptable state without subsequent radiographic progression in rheumatoid arthritis: results from a followup MRI study of 254 patients in clinical remission or low disease activity. J Rheumatol 2014;41:398-406. 